Subscriber access provided by King Abdullah University of Science and Technology Library

\title{
Article
}

\section{Identification and experimental characterization of an extremophilic brine pool alcohol dehydrogenase from single amplified genomes}

Stefan W. Grötzinger, Ram Karan, Eva Strillinger, Stefan Bader, Annika Frank, Israa S. Al Rowaihi, Anastassja Akal, Wiebke Wackerow, John A. Archer, Magnus

Rueping, Dirk Weuster-Botz, Michael Groll, Jörg Eppinger, and Stefan T. Arold

ACS Chem. Biol., Just Accepted Manuscript • DOI: 10.1021/acschembio.7b00792 • Publication Date (Web): 30 Nov 2017

Downloaded from http://pubs.acs.org on December 5, 2017

\section{Just Accepted}

"Just Accepted" manuscripts have been peer-reviewed and accepted for publication. They are posted online prior to technical editing, formatting for publication and author proofing. The American Chemical Society provides "Just Accepted" as a free service to the research community to expedite the dissemination of scientific material as soon as possible after acceptance. "Just Accepted" manuscripts appear in full in PDF format accompanied by an HTML abstract. "Just Accepted" manuscripts have been fully peer reviewed, but should not be considered the official version of record. They are accessible to all readers and citable by the Digital Object Identifier (DOI®). "Just Accepted" is an optional service offered to authors. Therefore, the "Just Accepted" Web site may not include all articles that will be published in the journal. After a manuscript is technically edited and formatted, it will be removed from the "Just Accepted" Web site and published as an ASAP article. Note that technical editing may introduce minor changes to the manuscript text and/or graphics which could affect content, and all legal disclaimers and ethical guidelines that apply to the journal pertain. ACS cannot be held responsible for errors or consequences arising from the use of information contained in these "Just Accepted" manuscripts. 
55

56

57

58

59

60

\section{SCHOLARONE ${ }^{m}$ Manuscripts}

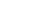

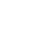

5

(8)

(2)

(3)

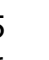

7

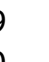

2

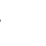

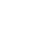

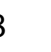

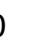

45

47

9

(1)
6 58 69 


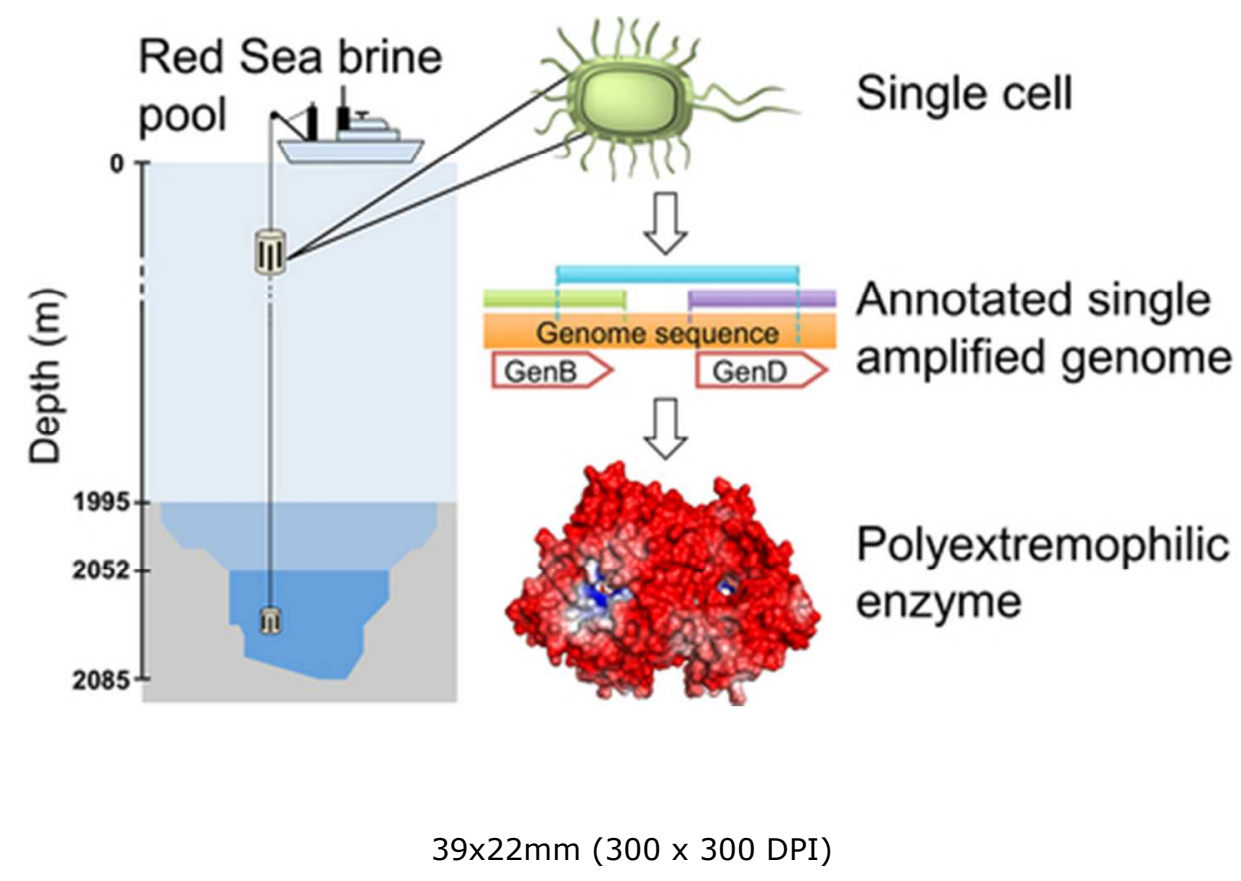

ACS Paragon Plus Environment 
1 Identification and experimental characterization of an extremophilic brine

\section{2 pool alcohol dehydrogenase from single amplified genomes}

\section{Authors}

5 Stefan W. Grötzinger ${ }^{1,2}$; Ram Karan ${ }^{3}$; Eva Strillinger ${ }^{2,3}$; Stefan Bader ${ }^{3}$; Annika Frank ${ }^{4}$; Israa S. Al

6 Rowaihi ${ }^{3}$; Anastassja Akal ${ }^{3,4}$; Wiebke Wackerow ${ }^{3}$; John A. Archer ${ }^{1}$; Magnus Rueping ${ }^{3}$; Dirk

$7 \quad$ Weuster-Botz ${ }^{2}$; Michael Groll ${ }^{4}$; Jörg Eppinger ${ }^{3}$; Stefan T. Arold ${ }^{1 *}$

$8 \quad{ }^{1}$ King Abdullah University of Science and Technology, Biological and Environmental Science and

9 Engineering Division, Computational Bioscience Research Center, Thuwal, Kingdom of Saudi Arabia

$10{ }^{2}$ Technical University of Munich, Department of Mechanical Engineering, Institute of Biochemical

11 Engineering, Garching, Germany

$12{ }^{3}$ King Abdullah University of Science and Technology, Physical Science and Engineering Division,

13 KAUST Catalysis Center, Thuwal, Kingdom of Saudi Arabia

$14{ }^{4}$ Technical University of Munich, Center for Integrated Protein Science Munich in the Department

15 Chemistry, Garching, Germany

$16 *$ Corresponding authors

\section{Correspondence}

18 Stefan T Arold: stefan.arold@kaust.edu.sa

19 Keywords

20 Halophilic; thermophilic; extremozyme; single-cell amplified genome; 5,6-dihydroxy NADPH;

21 biotechnology 


\section{Abstract \\ 23 Because only $0.01 \%$ of prokaryotic genospecies can be cultured and in situ observations are often \\ 24 impracticable, culture-independent methods are required to understand microbial life and harness \\ 25 potential applications of microbes. Here, we report a methodology for the production of proteins with \\ 26 desired functions based on single amplified genomes (SAGs) from unculturable species. We use this \\ 27 method to resurrect an alcohol dehydrogenase (ADH/D1) from an uncharacterized halo-thermophilic \\ 28 archaeon collected from a brine pool at the bottom of the Red Sea. Our crystal structure of 5,6- \\ 29 dihydroxy NADPH-bound ADH/D1 combined with biochemical analyses reveal the molecular \\ 30 features of its halo-thermophily, its unique habitat adaptations, and its possible reaction mechanism \\ 31 for atypical oxygen activation. Our strategy offers a general guide for using SAGs as a source for \\ 32 scientific and industrial investigations of 'microbial dark matter'. \\ 33}


34 The availability of new genetic information, which grew exponentially during the first two decades of

35 the twenty-first century, has fueled hopes of a biotechnological revolution ${ }^{l}$. However, experimental

36 research still focuses on a surprisingly narrow niche of life's rich versatility. Although 60 major microbial lines of descent (phyla or divisions) have been identified bioinformatically, $88 \%$ of all

38 isolated microbes are members of just four bacterial phyla ${ }^{2}$. Currently, a maximum of $0.3 \%$ of the

$3910^{6}-10^{8}$ prokaryote genospecies can be cultured and hence studied systematically ${ }^{3,4}$. Many

40 scientifically and biotechnologically interesting species thrive under unconventional conditions and

41 evade isolation. Remote locations and low cell densities further impede cell isolation and cultivation

42 from many extremophilic habitats. The vast majority of bacteria and archaea have thus not yet been

43 experimentally investigated ${ }^{5}$. This "microbial dark matter" constitutes an extremely rich and largely

44 untapped resource. Given that most enzymes currently used in industry originate from either fungi or

45 mesophilic bacteria ${ }^{6}$, experimental assessment of gene products of extremophilic bacteria and archaea

46 promises to yield active biomaterials with unprecedented properties.

48 Culture-independent methods, which have gained traction after the advent of next-generation

49 sequencing, are expected to facilitate the mining of the microbial dark matter. The widely used

50 metagenomics approach however suffers from the complexity of generated sequence data, intrinsic

51 environmental contamination, and genomic heterogeneity ${ }^{7}$. Recently, the availability of single-cell

52 amplified genome (SAG) sequencing has eliminated metagenomic bottlenecks through the physical

53 separation of the genomic material of individual uncultured cells ${ }^{5}$. By allowing to obtain the genomes

54 of entire organisms, recent advances in single-cell genomics have enabled the bioinformatic

55 description of completely new phyla, adding to the knowledge base necessary for the development of

56 commercial applications ${ }^{8}$.

57 Despite these developments, only a few novel extremozymes were described using culture-

58 independent methods. One of the main reasons for a lack of targeted 'translation' of the wealth of

59 genetic and bioinformatic information into specific recombinant proteins lies in the challenges of

60 reliably annotating genomic data from distantly related organisms. Single-cell genomics relies on 
61 bioinformatic annotation algorithms, pipelines ${ }^{9}$ or fully automated data warehousing systems ${ }^{10}$, all of

62 which depend on existing functional annotations. Correspondingly, annotation algorithms deliver

63 valid results for organisms from well-investigated branches of the tree of life ${ }^{10}$, while the reliability of

64 such results decreases with increasing phylogenetic distance to the next experimentally verified data

65 point ${ }^{9}$. Since bioinformatics algorithms are extrapolated from established functions, high-throughput

66 data processing may even act as a filter that conceals novel traits from annotated genomes. The

67 exponential growth of genetic information, which exceedingly outpaces experimental verification

68 efforts, has amplified this problem. Today, only $0.15 \%$ of the genes in the UniProt database are

69 annotated by data curated from experimental evidence on the protein level. The use of selected

70 sequencing data from diverse environments as basis for experimental verification could fill important

71 gaps in our understanding of the tree of life. However, this would require in-depth experimental

72 characterization of gene products from unculturable organisms.

73 Especially for genes from extremophiles, experimental characterization is hampered by the lack of

74 generic expression systems that allow recombinant protein production under the extreme conditions

75 required for native protein folding. This is an important limitation because experimental evidence of

76 selected gene products drawn from diverse environments will improve the precision of annotation

77 algorithms ${ }^{9}$. Ultimately, the experimental assessment of genes from such environments is required to

78 yield new resources for the huge global market for industrial enzymes ${ }^{11}$.

79

80 Previously, we described a general bioinformatics approach to improving the functional annotation of

81 genes from distantly related organisms ${ }^{9}$. Here, we demonstrate a novel methodology for the targeted

82 selection and recombinant expression of a SAG-derived enzyme with the desired function - in our

83 case, an alcohol dehydrogenase from a halo-thermophilic environment. The selected archaeal gene

84 was sampled from one of the most remote habitats on earth, the Discovery Deep brine pool at the

85 bottom of the Red Sea (2'141m depth, $44.8^{\circ} \mathrm{C}, 26.2^{\prime} \%$ salt), and annotated as an alcohol

86 dehydrogenase $(\mathrm{ADH})$. Although we estimated that the reliability of the annotation was high, we

87 observed surprising characteristics from the biochemical and structural characterization of the gene

88 product, including an uncommon $\mathrm{Mn}^{2+}$ center, substrate preference, superoxide dismutase (SOD)-like 
89 oxygen activation and NADPH cofactor modification. These characteristics were not predicted during 90 annotation. Comparison with mesophilic enzymes sheds new light on documented ADH features and

91 revealed adaptations to the halo-thermophilic environment. Our results provide a roadmap for mining

92 uncultured SAGs to broaden our understanding of inaccessible species and their habitats as well as to 93 inspire industrial applications. 


\section{RESULTS AND DISCUSSION}

95 The aim of our study was to use SAGs as sources for the production and biochemical assessment of

96 enzymes from extremophiles. Our rationale was to combine (i) SAG-adapted bioinformatics for

97 confident selection of a gene of interest, (ii) molecular biology and engineering to allow its expression

98 in a bacterial host, and (iii) chemical and biophysical methods to assess the produced protein's

99 function and enzymatic features.

100

101 SAGs as a gateway to proteins from unculturable species

102 During the Third KAUST Red Sea expedition, 11 liquid environmental samples were collected from

103 five brine pools in the Red Sea. Cell-sized particles were then isolated by filtration (Figure 1).

104
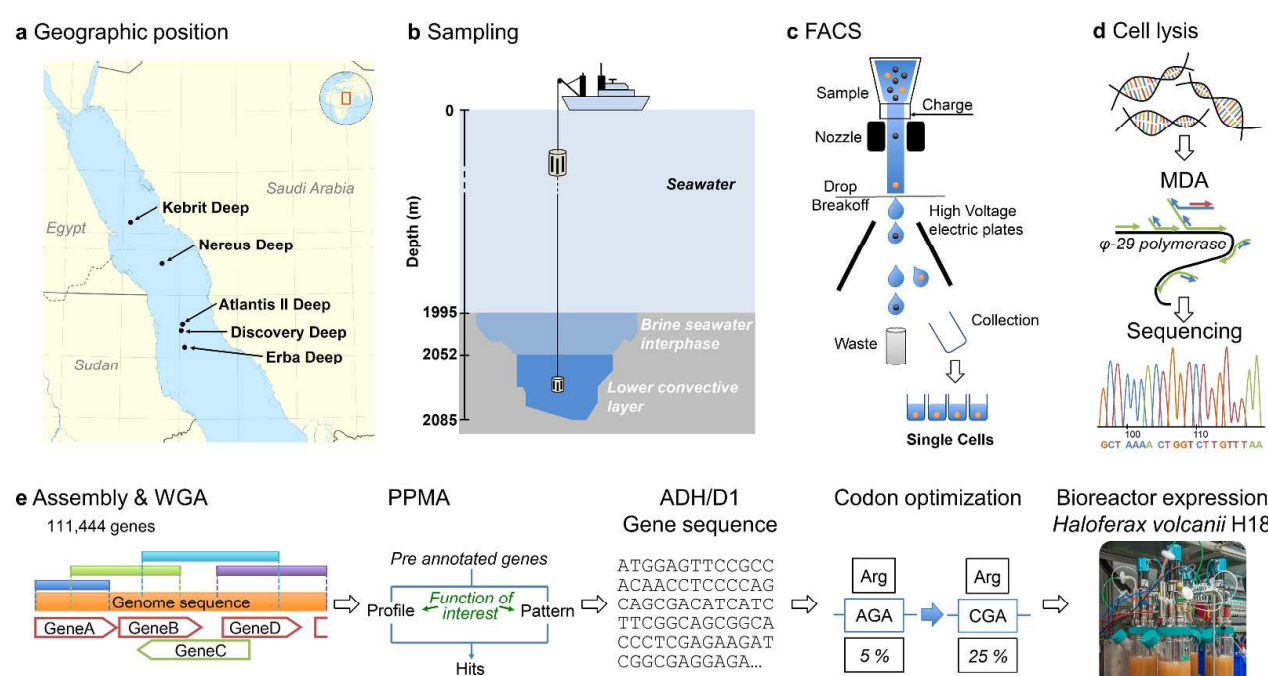

PPMA
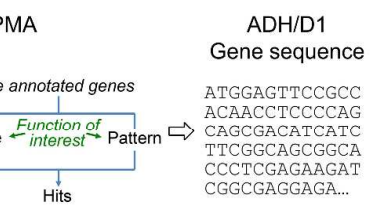

Codon optimization Bioreactor expression in
Haloferax volcanii $\mathrm{H} 1895$

105

106 Figure 1: From the extremophilic environment to the ADH/D1 protein. a) Geographical locations

107 of the five sampled Red Sea brine pools. b) Specimen collection using a rosette sampler. c) FACS to

108 triage DNA-stained single cells. d) Lysis of single cells to harvest their DNA; multiple displacement

109 amplification (MDA) using the $\varphi$ polymerase to amplify the DNA; DNA sequencing. e) Assembly of

110 the sequenced DNA fragments and whole genome annotation using the INDIGO data warehouse ${ }^{10}$;

111 use of the profile and pattern matching algorithm (PPMA) ${ }^{9}$ to increase reliability of the annotation of 
112 specific genes of interest; selection of the ADH/D1 gene as the best hit; codon optimization of the

$113 \mathrm{ADH} / \mathrm{D} 1$ gene to be used in the halophilic expression host Haloferax volcanii; expression of ADH/D1

114 in large-scale bioreactors.

115

116 Particles reacting to the DNA stain were separated into single cells using fluorescence-activated cell

117 sorting (FACS). The isolated DNA was amplified and sequenced, and the resulting genomes were

118 assembled and annotated using the INDIGO data-warehouse system ${ }^{10}$. The 11 liquid samples resulted

119 in 87 SAGs covering 16 different taxonomic groups, providing a narrow but deep insight into the

120 diversity of organisms of these habitats. The assembly and initial annotation yielded 111,444 genes ${ }^{9}$.

121 We selected an ADH gene (enzyme commission (EC) numbers 1.1.1.1. and 1.1.1.2) as our target for

122 the following reasons: (i) ADHs, which catalyze the interconversion between alcohols, aldehydes, and

123 ketones, can produce enantiopure chemical entities of biotechnological interest ${ }^{12}$; (ii) ADHs can be

124 used in a wide range of applications, such as biosensor-based diagnostics and fuel-cell technologies ${ }^{13}$;

125 (iii) the availability of spectrophotometric activity assays and a wealth of structural and functional

126 information makes ADHs a suitable model enzyme to understand protein adaption to halo-

127 thermophilic conditions and to correlate the enzyme's activity profile with conditions inside the host-

128 cell, such as salt concentration, cofactor availability and $\mathrm{pH}$.

129

130 To select an ADH gene for our study, we chose three brine pool environments (Atlantis II Deep,

131 Discovery Deep and Kebrit Deep) with temperatures above $44^{\circ} \mathrm{C}$ and/or with salinity above $13 \%$

$132(\mathrm{w} / \mathrm{v})$ because of the scientific and industrial interest of these conditions. This choice resulted in 48

133 SAGs $\left(63,816\right.$ non-rRNA genes). We next used the PPM algorithm ${ }^{9}$ to increase the reliability of our

134 gene function annotation. Accordingly, we used the AutoTECNo script of PPMA to translate the 239

135 EC entries listed for "ADH" in the Braunschweig Enzyme Database (BRENDA) ${ }^{14}$ into the

136 corresponding 148 gene ontology (GO)-terms and 20 PROSITE-IDs. The resulting two queries were

137 imported into INDIGO separately and processed, resulting in 826 GO-terms and 419 PROSITE-IDs, 
138 representing 269 genes (one gene can have multiple attributes). Next, the PPM Processor script of

139 PPMA automatically combined the query results and ranked the 269 genes into 31 groups, according

140 to GO-terms and PROSITE-IDs found per gene.

141

142 From these genes, we chose the hypothetical protein AKJ65_00115 (GenBank: KXA95890.1; in the

143 following ADH/D1) from Discovery Deep (at 2,141 m depth, 216 bar pressure, $\mathrm{pH} 6.4,44.8^{\circ} \mathrm{C}$ and

144 salt concentration of $26.2 \%(\mathrm{w} / \mathrm{v}))$. We selected ADH/D1, because (i) it was the highest-ranked

145 general ADH using a standard cofactor according to the PPM algorithm ${ }^{9}$; (ii) it stemmed from the

146 unculturable archaeon MSBL1, whose genome had been analyzed bioinformatically ${ }^{15}$; (iii) it would

147 be the first 'iron-type' halophilic archaeal ADH (InterPro ID IPR018211) to be structurally

148 characterized; and (iv) it showed low sequence identity (less than 40\%) to annotated genes in the

149 NCBI.

150

151 Expression of the in silico-determined, codon-optimized ADH/D1 gene in E. coli resulted in an

152 insoluble protein, presumably because the cytosolic $\mathrm{KCl} / \mathrm{NaCl}$ concentrations were insufficient for

153 correct folding. Therefore, we thought to use the halophilic expression system Hfx. volcanii to express

$154 \mathrm{ADH} / \mathrm{D} 1$. We established that $H f x$. volcanii uses codons very similarly to Halobacterium sp. NRC-1,

155 which is included in freely available codon-optimization programs (Supplementary Table 1). We

156 therefore codon-optimized ADH/D1 for Halobacterium sp. NRC-1. This approach was successful and

157 stirred-tank bioreactor expression using $H f x$. volcaniil ${ }^{16}$ produced more than $100 \mathrm{mg} \mathrm{L}^{-1}$ of pure codon-

158 optimized ADH/D1 after a one-step Ni-NTA purification step.

159

160 Structure and halo-thermophilic adaptations

161 We determined the crystal structure of recombinant ADH/D1 to $2.1 \AA$ resolution (PDB: 5yvm). The

162 final model included ADH/D1 residues 1-400 and two additional residues from the $\mathrm{N}$-terminal linker

163 (introduced to increase the accessibility of the his ${ }_{6}$-tag) and the first histidine residue of the his ${ }_{6}$-tag 
164 itself. ADH/D1 adopts the canonical two-lobed structure of this class of iron-type ADH, where the C-

165 terminal domain $(\mathrm{ADH} / \mathrm{D} 1$ residues $186-400)$ is entirely composed of $\alpha$-helices and the N-terminal

166 domain contains an extended $\beta$-strand-like region, followed by an $\alpha / \beta$-Rossmann fold (residues $8-$

167 186), consisting of six parallel $\beta$-strands and six $\alpha$-helices (Figure 2a,b).

168

a

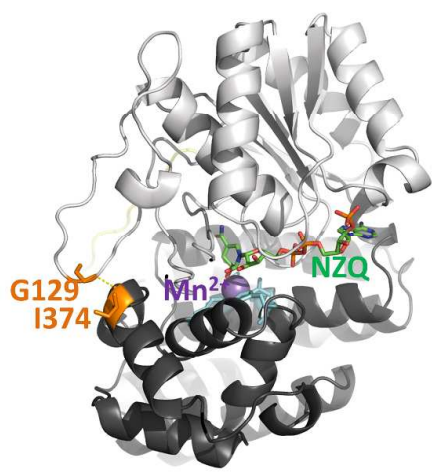

c

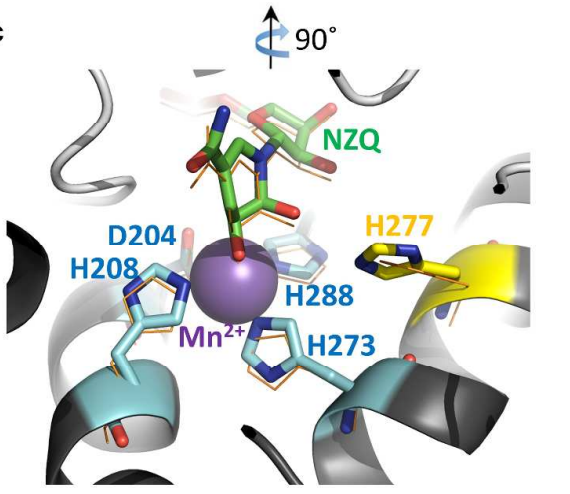

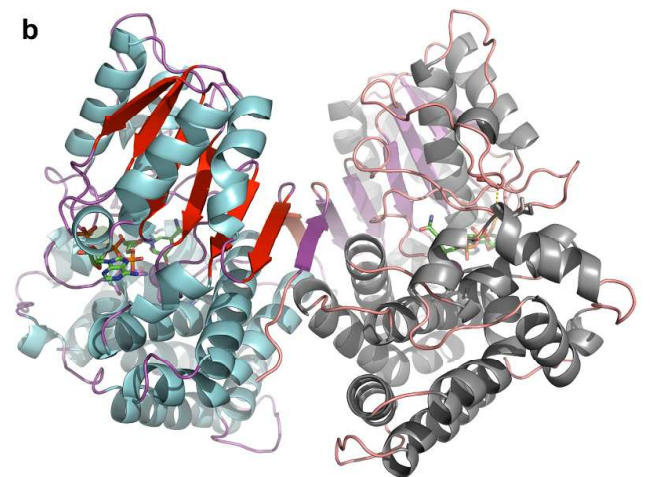

d

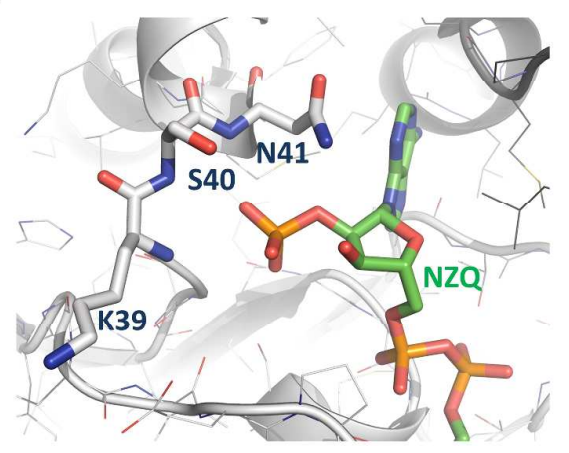

169

170

171 N-terminal lobe (dark grey) and the C-terminal lobe (light grey) are linked by a backbone hydrogen

172 bond between Gly129 and Ile374 (orange). The catalytic metal $\mathrm{Mn}^{2+}$ (magenta sphere) bound in the

173 active site (cyan residues; see c) and the cofactor NZQ $\left(5 S, 6 S-\mathrm{NADPH}(\mathrm{OH})_{2}\right.$, green sticks) are

174 highlighted. b) The ADH/D1 dimer, with the secondary structure highlighted in different colors for 175 each monomer. c) The ADH/D1 active center formed by Asp204, His208, His273 His288 (cyan) and

176 His277 (yellow), superimposed onto the active center of the E. coli homolog YqhD (formed by

177 Asp194, His198, His267, His281, and His271; orange lines). d) Binding pocket of the phosphate 178 group of NZQ. 
180 ADHs of the iron-type dehydrogenase class can bind to either NADH or NADPH. Although we

181 incubated ADH/D1 with NADH prior to crystallization, we found that the electron density revealed

182 the presence of a phosphate on the 2' position of the ribose ring, as expected for NADPH. The

183 backbones of residues Lys39, Ser40 and Asn41 form a pocket that accommodates the phosphate. The

184 phosphate moiety is hydrogen bonded by backbone nitrogens and the Asn41 side chain (Figure 2d).

185 This specific pocket provided a rationale for the strong preference of ADH/D1 for NADPH rather

186 than NADH.

187

$188 \mathrm{ADH} / \mathrm{D} 1$ formed a tight dimer through $\beta$-sheet hydrogen bonds between the $\mathrm{N}$-terminal $\beta$-strand of

189 one molecule with the first $\beta$-sheet of the Rossmann fold of the second molecule. Additional

190 interactions were contributed by helices two and three of the C-terminal lobe, resulting in a total of

$1911,560 \AA^{2}$ of buried surface area per subunit in the interface (10.4\% of total monomer surface). Small-

192 angle X-ray scattering (SAXS) confirmed the presence of this crystallographic dimer under a wide

193 range of conditions (Supplementary Table 2). The two lobes of each monomer formed a $\sim 26 \AA$ long

194 channel in which $\mathrm{NAD}(\mathrm{P}) \mathrm{H}$ can bind from one side, and the substrate enter from the other, with the

195 active-site metal between them (Figure 2a,c). The length of the channel suggested a preference of

196 ADH/D1 for long-chain rather than short-chain alcohols. Substrate conversion analysis confirmed that

$197 \mathrm{ADH} / \mathrm{D} 1$ prefers extended primary alcohols, such as cinnamyl alcohol $\left(\approx 1.57 \mu \mathrm{mol} \mathrm{min} \mathrm{mg}^{-1}\right)$ or

198 prenol $\left(\approx 1.32 \mu \mathrm{mol} \mathrm{min} \mathrm{mg}^{-1}\right)$ to shorter chains, such as butanol $\left(\approx 0.60 \mu \mathrm{mol} \mathrm{min}{ }^{-1} \mathrm{mg}^{-1}\right)$ or ethanol

$199\left(\approx 0.04 \mu \mathrm{mol} \mathrm{min}^{-1} \mathrm{mg}^{-1}\right)$ (Figure 3a,b; Supplementary Table 3; Supplementary Figure 1a-f).

200 
201

202

203

204

205

206

207

208

209

210

211

212

213

214

215

216

217

218

219
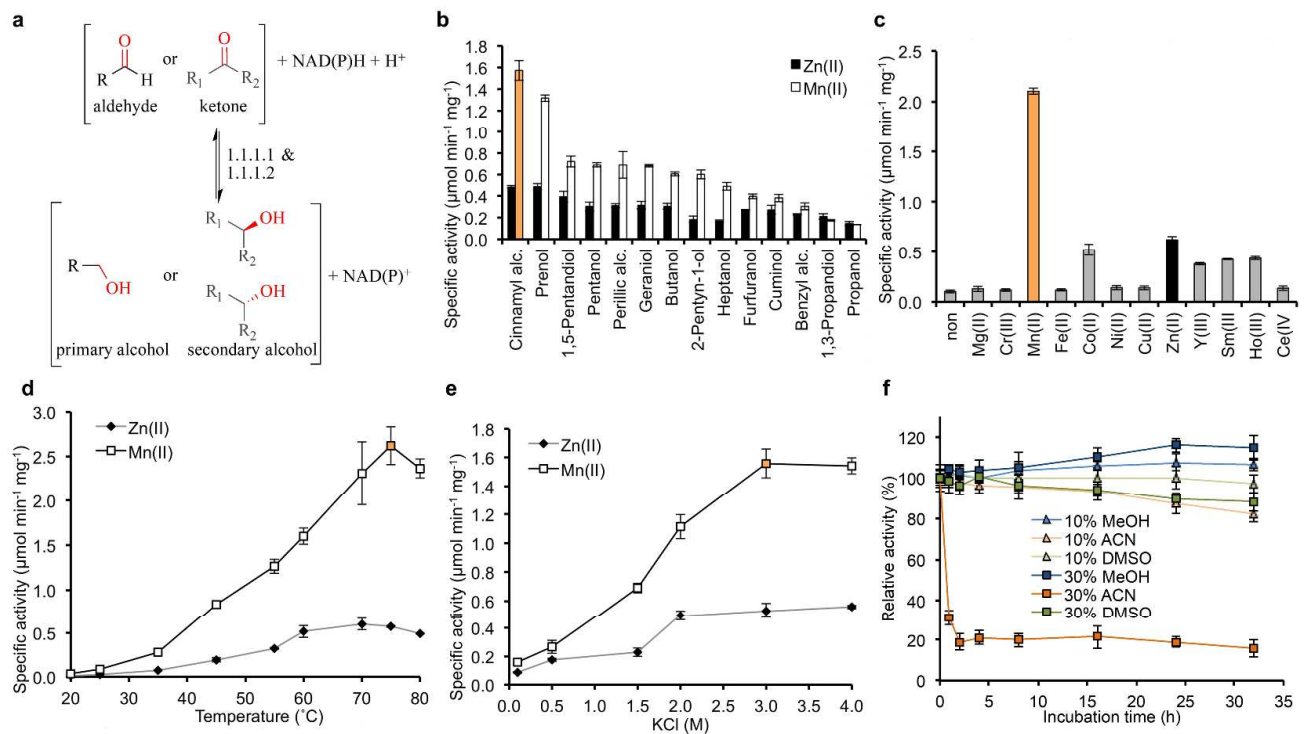

Figure 3: Activity of ADH/D1. a) Reaction scheme for ADHs. b) Specific activity with different substrates of $\mathrm{ADH} / \mathrm{D} 1$ with $\mathrm{Mn}^{2+}$ or $\mathrm{Zn}^{2+}$. c) Specific activity assessed spectrophotometrically by measuring the cofactor oxidation via optical density changes at $\lambda=340 \mathrm{~nm}$. ADH/D1 was dialyzed overnight with EDTA prior to adding different metal ions. $\mathrm{Mn}^{2+}$ (orange) and $\mathrm{Zn}^{2+}$ (black) are highlighted. d) ADH/D1 activity at increasing temperatures with $\mathrm{Mn}^{2+}$ or $\mathrm{Zn}^{2+}$. e) Specific activity of $\mathrm{ADH} / \mathrm{D} 1$ at increasing $\mathrm{KCl}$ concentrations in the presence of $\mathrm{Mn}^{2+}$ or $\mathrm{Zn}^{2+}$. f) Activity after incubation with the indicated amount of solvents for different time periods at room temperature. MeOH: methanol, ACN: acetonitrile, DMSO: dimethyl sulfoxide.

The overall and secondary structures of both the monomer and the dimer of the archaeal ADH/D1 were similar to the structures of mesophilic or thermophilic bacterial ADHs (RMSDs to closest monomeric homologs were 1.9-2.3 $\AA$, Supplementary Table 4). Structures of homologous halophilic archaeal ADHs have not yet been published. This similarity suggested that halothermophilic adaptation of $\mathrm{ADH} / \mathrm{D} 1 \mathrm{did}$ not require gross structural alterations. Compared to its homologs, $\mathrm{ADH} / \mathrm{D} 1$ displayed the most negative dimer surface charge, resulting mostly from an exceptionally high number of aspartic and glutamic acids (Figure 4, Supplementary Table 5, Supplementary Table 6). Conversely, the dimerization surface of the monomer retained the character of the mesophilic charge, allowing the formation of a stable dimer. 


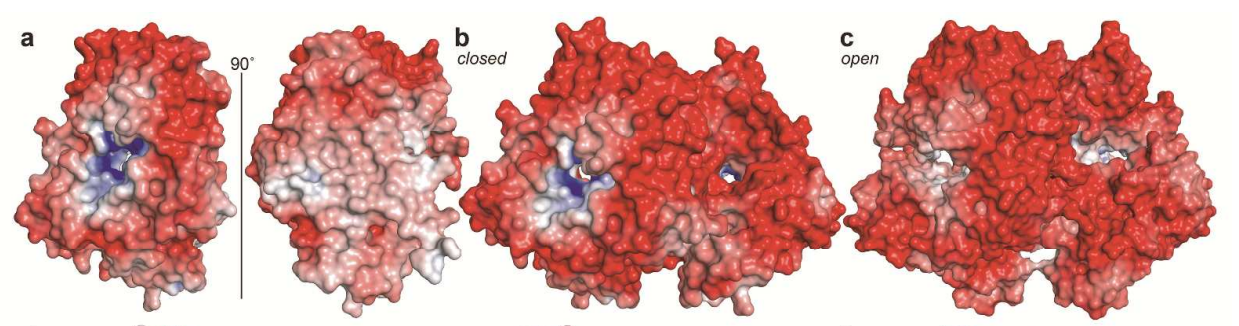

222 Figure 4: Surface charge of ADH/D1 and its homologs. The surface of ADH/D1 is color-ramped

223 from red (negative) to blue (positive). a) ADH/D1 monomer, viewed from the positively charged

224 cofactor binding site (left) and from the less-charged dimerization site (right). b) Closed configuration

225 of the ADH/D1 dimer oriented as in Figure 2b. c) Modeled structure of the open ADH/D1 dimer. d-

226 o) Surface charges of structural homologs: d) 3ox4 (Z. mobilis), e) 3owo (Z. mobilis), f) $1 \mathrm{rrm}$ (E.

227 coli), g) 3bfj (K. pneumonia), h) 4fr2 (O. oeni), i) 1oj7 (E. coli), j) 4qgs (E. coli), k) 3w5s (Rhizobium

228 sp. MTP), 1) 3jzd (R. eutropha), m) $1 \mathrm{vlj}($ T. maritima $), \mathrm{n}) 1 \mathrm{o} 2 \mathrm{~d}($ T. maritima $)$, o) $3 \mathrm{zdr}(G$. 
229 thermoglucosidasius). Th: thermophile; open and closed structures are indicated. Units:

$230 \mathrm{kcal}\left(\mathrm{mol}^{*} \text { electron) }\right)^{-1}$ (vs. salt-free buffer).

231 A highly negative surface charge is generally seen as the main driving force for halo-adaption. The 232 negatively charged surface residues, in particular glutamic acid, bind hydrated ions and therefore form 233 a highly-ordered solvation shell which prevents aggregation and increases protein solubility ${ }^{17}$.

234 Adaptation to high temperatures was apparent in features known to increase protein stability,

235 particularly the tethering of both protein termini to the core and the exceptionally high number of 236 hydrogen bonds within the monomer and ionic bonds across the dimer interface (Supplementary

237 Table 7). We also observed a unique feature of ADH/D1 in that both lobes of each monomer were 238 held together by an additional backbone hydrogen bond (between Gly129 and Ile374; Figure 2a). The 239 number of bulky hydrophobic residues of $\mathrm{ADH} / \mathrm{D} 1$ remained within the mesophilic range and did 240 neither follow the halophilic nor thermophilic trends (Table 1). Thus, ADH/D1 displayed features 241 common to halophilic and thermophilic proteins, as well as unique adaptations.

243 Table 1: Trends for halo- and thermoadaption in ADH/D1 in comparison to mesophilic

\section{4 homologs} 245

\begin{tabular}{|c|c|c|c|}
\hline Characteristic & halophilic & thermophilic & ADH/D1 \\
\hline Surface charge & negative $^{a, b}$ & unchanged $^{c}$ & negative \\
\hline Solvation shell & $\begin{array}{l}\text { highly ordered multi- } \\
\text { layered }^{b}\end{array}$ & - & ordered \\
\hline Surface hydrophobicity & decreased $^{b}$ & $\begin{array}{l}\text { unchanged }{ }^{c} \text { or slightly } \\
\text { decreased }^{d}\end{array}$ & decreased \\
\hline Charged residues on surface & increased $^{a}$ & unchanged $^{d}$ & increased \\
\hline Asp and Glu (neg. charged) & increased $^{a}$ & unchanged $^{c, d}$ & increased \\
\hline $\begin{array}{l}\text { Phe, Ile and Leu } \\
\text { (hydrophobic) }\end{array}$ & decreased $^{a, b}$ & unchanged $^{c, d}$ & unchanged \\
\hline $\begin{array}{l}\text { Ser and Thr (borderline } \\
\text { hydrophobic) }\end{array}$ & increased $^{b}$ & unchanged $^{c, d}$ & increased \\
\hline
\end{tabular}

\footnotetext{
${ }^{a}$ reference ${ }^{18}$

${ }^{b}$ reference ${ }^{17}$

${ }^{c}$ reference ${ }^{19}$

${ }^{d}$ reference ${ }^{20}$
} 
Gly, Ala (small)

Lys (pos. charged)

Cys and Ser (short-range interactions and thermolabile)

Arg and Tyr (short and longrange interactions)

Salt bridges (intra- and intermolecular)

Hydrogen bonds (intra- and intermolecular)

Hydrophobic interactions

Overall structure

Total amino acid content

Total amino acid content

Secondary structure content

Oligomerization

Structural flexibility

Salt withdrawal

Metals

Packing volume

$\mathrm{N}$ - and C-termini

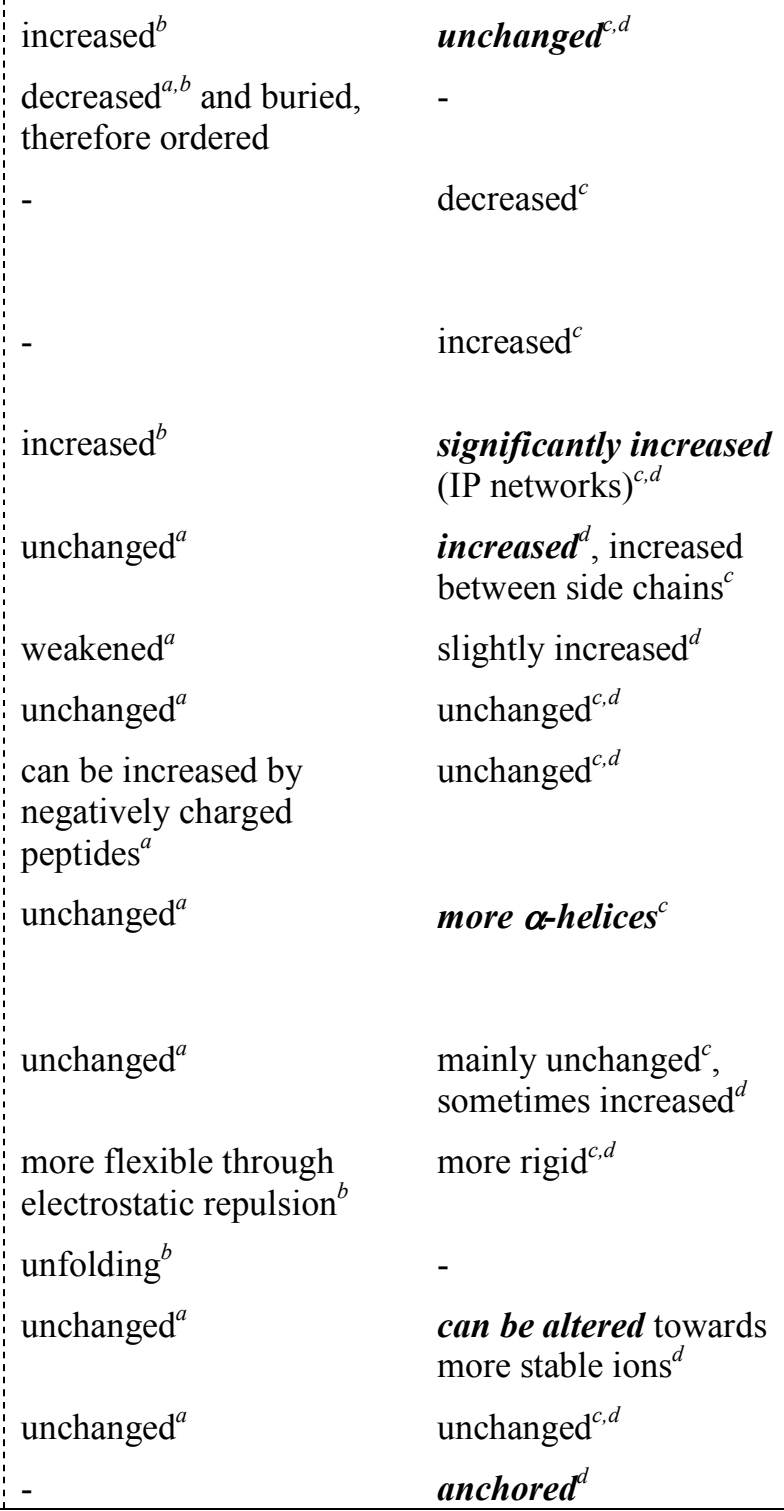

\section{SAG enzymes as probes for inaccessible habitats}

248 Microbes adapt their proteins to perform under the conditions of their native environments. Hence,

249 experimental analysis of SAG-derived enzymes might provide insights into life in inaccessible

250 regions. The conditions of the Discovery Deep sample collection site of MSBL1 have been

251 established, and the enzymatic activity of ADHs is well characterized, allowing us to determine how

252 the idiosyncrasies of ADH/D1 reflect the habitat and biology of MSBL1. 
1

2

3

4

5

6

7

8

9

10

254 The catalytic activity of $\mathrm{ADH} / \mathrm{D} 1$ peaked at $70-75^{\circ} \mathrm{C}$ (Figure 3d). At this temperature, enzymatic 255 activity ceased after $1.5 \mathrm{~h}$. Conversely, at $40-45^{\circ} \mathrm{C}, \mathrm{ADH} / \mathrm{D} 1$ remained more than $60 \%$ catalytically 256 active after $6 \mathrm{~h}$ (Supplementary Figure 2a). With respect to salinity, the activity of ADH/D1 was 257 highest between 3-4 M KCl and $\mathrm{ADH} / \mathrm{D} 1$ remained stable in the presence of $2 \mathrm{M} \mathrm{NaCl}$ or more for 258 more than $24 \mathrm{~h}$ (Supplementary Figure $\mathbf{2 b}$ ). The high stability and activity of ADH/D1 under high 259 salt conditions suggested that MSBL1 uses a 'high-salt-in' strategy to live under ambient highly saline 260 conditions, rather than actively reducing cytosolic salt concentrations. Thus, our data suggest that $261 \mathrm{ADH} / \mathrm{D} 1$ is optimized for stability rather than for activity under its natural conditions.

We found that the oxidative reaction of ADH/D1 strongly increased between a $\mathrm{pH}$ of 9.6-10.2 and 264 then dropped rapidly at higher values (Supplementary Figure 2c). The addition of the reducing agent $265 \beta$-mercaptoethanol (BME) lowered the $\mathrm{pH}$ of ADH/D1's peak activity to 9.0-9.5 (Supplementary

266 Figure 2d). This effect of BME was also noted for the homologous E. coli $\mathrm{YqhD}^{21}$. The reasons for 267 this effect remain unclear because these ADHs do not form disulfide bonds nor have conserved 268 solvent-exposed cysteines. At the Discovery Deep $\mathrm{pH}$ of 6.4, ADH/D1 catalyzes the reduction 269 reaction, strongly suggesting that this is its biologically dominant catalytic activity (Supplementary 270 Figure 3a,b).

272 Despite its specific binding pocket to accommodate NADPH, ADH/D1 was also active in the 273 presence of either $\mathrm{NAD}^{+}$or $\mathrm{NADP}^{+}$. At high cofactor concentrations $(12 \mathrm{mM})$, activity with $\mathrm{NADP}^{+}$ $274\left(0.1 \mu \mathrm{mol} \mathrm{min} \mathrm{mg}^{-1}\right)$ was markedly lower than with $\mathrm{NAD}^{+}\left(1.6 \mu \mathrm{mol} \mathrm{min} \mathrm{mg}^{-1}\right)($ Supplementary 275 Figure 3c,d), suggesting that the slow release of the stronger-bound NADPH after catalysis became 276 the rate-limiting factor. Increasing $\mathrm{NAD}^{+}$concentrations accelerated the enzymatic activity until it 277 reached a plateau at $10 \mathrm{mM}$ (Supplementary Figure 3e). The apparent adaptation to strong binding 278 of NADPH, despite the resulting slow reaction rate, might indicate a low abundance of substrate 279 and/or cofactor $(\mathrm{NAD}(\mathrm{H})$ or $\mathrm{NADP}(\mathrm{H}))$ under natural conditions that would make strong cofactor 
280 binding beneficial. ADH/D1's natural role might therefore be to perform a housekeeping reduction

281 reaction.

282

283 SAG-derived ADH reveals new features of ADHs

284 While ADHs have been studied in great detail, our analysis of a SAG-derived remote archaeal

285 homologs shed new light on several features of this class of enzymes. Although ADH/D1 was

286 annotated as iron-dependent (IDs: PS00913 and PS00060), X-ray absorption scans of ADH/D1

287 crystals showed a clear signal for manganese (Supplementary Figure 4a), which is compatible with

288 electron density features we observed. Spectrometric analysis of the oxidation of alcohols by

$289 \mathrm{ADH} / \mathrm{D} 1$ showed that different metals are accepted as cofactors and increase activity, revealing an

290 unusually high metal promiscuity for $\mathrm{ADH} / \mathrm{D} 1 . \mathrm{Mn}^{2+}$ increased the basal activity substantially more

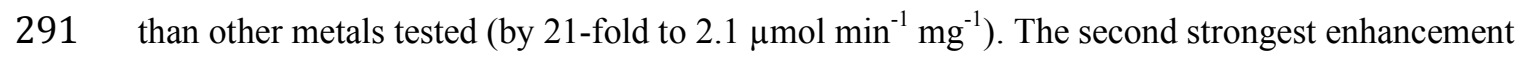

292 occurred with $\mathrm{Zn}^{2+}$ (6-fold). $\mathrm{Co}^{2+}, \mathrm{Ho}^{3+}, \mathrm{Sm}^{3+}$ or $\mathrm{Y}^{3+}$ ions increased activity between 4 and 5-fold,

293 whereas $\mathrm{Fe}^{2+}$ showed no increase in activity (Figure 3c). Besides their influence on ADH/D1 activity,

294 the different metals also affected protein stability. Excess $\mathrm{Mn}^{2+}$ increased the aggregation temperature

$295\left(T_{a g g}\right)$ of $\mathrm{ADH} / \mathrm{D} 1$ by up to $10^{\circ} \mathrm{C}$ compared with excess $\mathrm{Zn}^{2+}$ (Supplementary Figure 2e). Notably,

$296 \mathrm{ADH} / \mathrm{D} 1$ is the only $\mathrm{ADH}$ reported to specifically use manganese; $\mathrm{Mn}^{2+}$ is a highly abundant metal in

297 the lower connectivity layer and the brine-water interface of Discovery Deep $(89.7 \pm 43.1 \mu \mathrm{M}$

298 and173.5 $\pm 15.1 \mu \mathrm{M}$, respectively $\mathrm{y}^{22}$ ). In the deep water overlaying the brine pool, the concentration of

$299 \mathrm{Mn}^{2+}$ was less than $1.8 \mu \mathrm{M}^{22}$ and it is a trace element in other areas of the Red $\mathrm{Sea}^{23}$.

300 Our analysis of the ADH/D1 electron density map revealed the presence of a modified NADPH. The

301 bound cofactor is hydroxylated in positions 5 and 6 of the nicotinamide ring, resulting in the $S, S$ -

302 stereoisomer. This 5S,6S-NADPH $(\mathrm{OH})_{2}$ modification is abbreviated to NZQ in the Protein Data Bank

303 (PDB), where it has only one entry as the ligand bound to the E. coli $\mathrm{ADH}$ YqhD $(1 \mathrm{oj} 7)^{21}$. The active

304 center of YqhD is similar to that of ADH/D1 (Figure 2c). Following hydroxylation, the size increase

305 in combination with the additional hydrogen bonds formed by the added oxygen atoms appeared to

306 render NZQ-binding almost irreversible, as NZQ is only released following $3 \mathrm{~h}$ of dialysis of 
$307 \mathrm{ADH} / \mathrm{D} 1$ with excess NADP at $50^{\circ} \mathrm{C}$ (Supplementary Table 8). Thus, the NZQ modification in

308 ADH/D1 would likely be strongly auto-inhibitory within the cell. This modification is probably a 309 non-physiological artifact of the aerobic conditions in our experiments because Discovery Deep has 310 anaerobic conditions. In support of an anaerobic lifestyle in the brine pool, a previous computational 311 genomic analysis of SAGs of MSBL1 failed to identify genes against oxidative stress in this $312 \operatorname{archaeon}^{15}$. However, it is unclear if there is a physiological role for NZQ in YqhD from the 313 facultative anaerobic E. coli.

315 The active center of ADH/D1 is similar to that of oxygen-activating enzymes like manganese

316 superoxide dismutases (Mn-SODs, Supplementary Figure 5a,b) and Rieske-dioxygenases (RDOs,

317 Supplementary Figure 5c). Both enzyme classes utilize an additional hydrogen-bonding glutamine

318 or histidine to facilitate oxygen activation. The position of the histidine relative to the metal center is 319 similar to the position of His277 in ADH/D1. Molecular dynamics simulations indicated that $\mathrm{Mn}^{2+}$

320 and His277 might facilitate superoxide binding similar to that observed for Mn-SODs

321 (Supplementary Figure 5d). Our crystallographic analysis of the ADH/D1 H277A mutant (PDB:

322 5yvr) (Supplementary Figure 5e) did not show features of a cofactor modification, in support of the 323 role played by His277 in the NZQ dihydroxylation mechanism. These data suggested that NZQ is 324 formed by a reaction sequence of initial oxygen activation resembling the reversed oxygen-release 325 reaction of Mn-SODs, followed by a dihydroxylation similar to the mechanism established for RDOs 326 (Supplementary Figure 5f).

328 Despite the strong similarity in active site composition and conformation (Figure 2c), resulting in the 329 same annotation as iron-dependent ADHs, ADH/D1 and E. coli YqhD significantly differ in their 330 metal/activity fingerprint. We found that YqhD's activity is enhanced by $\mathrm{Co}^{2+}(\sim 9$-fold), closely 331 followed by $\mathrm{Mn}^{2+}$ and $\mathrm{Ni}^{2+}$ ( 6-fold). Most of the other metals tested only marginally enhanced the 332 activity over basal levels (Supplementary Figure 4b). Thus, even subtle stereochemical changes can 
333 drastically alter the preference, amplitude, and level of specificity and the type of metal bound to

334 ADHs, making the prediction of metal preference highly challenging.

335

$336 \mathrm{ADH} / \mathrm{D} 1$ and homologs contain two lobes; their relative orientation varies between the crystal

337 structures of the homologs, showing open, intermediate, and closed states (Supplementary Figure

$338 \mathbf{4}, \mathbf{d})$. None of the ADH structures in the open configuration showed a bound cofactor. The

339 enlargement of the binding channel and reduction of interactions between the cofactor and enzyme in

340 intermediate states compared with closed states (Supplementary Table 7) strongly suggested that

341 cofactor release requires the open conformation. To our knowledge, this open/closed mechanism has

342 not yet been described for this class of ADHs, but it has for the structurally different ADHs from

343 horse $\operatorname{liver}^{24}$ and yeast ${ }^{25}$.

344 In ADH/D1, the closed form appeared to be particularly stable. NZQ was partially or fully replaced

345 by $\mathrm{NADP}^{+}$only after dialysis at $50^{\circ} \mathrm{C}$ for $3 \mathrm{~h}$ in the presence of $1 \mathrm{mM} \mathrm{NADP}^{+}$as assessed by a series

346 of 1.9-2.5 Å crystal structures (PDB: 5yvs) (Supplementary Table 8). In agreement, SAXS data

347 collected from ADH/D1 that was incubated with EDTA, different cofactors, different salt

348 concentrations, BME or heated prior to or during the measurement did not differ significantly. The

349 dimeric closed conformation fitted well to the data collected under all conditions (Supplementary

350 Table 2). Substrate conversion and Michaelis-Menten kinetics showed a first-order reaction, although

351 the enzyme requires three components, suggesting that the transition between open and closed states

352 is the rate-determining step (Supplementary Figure 1a-c).

354 The biotechnological potential of ADH/D1

355 Beyond the thermostability of $\mathrm{ADH} / \mathrm{D} 1$, its halotolerance is of interest for biotechnological

356 applications, because high salt concentrations correspond to low water activity and hence to increased

357 solvent tolerance. Indeed, $\mathrm{Mn}^{2+}$-bound $\mathrm{ADH} / \mathrm{D} 1$ retained $\geq 40 \%$ activity in the presence of $30 \%(\mathrm{v} / \mathrm{v})$

358 DMSO in $1-3 \mathrm{M} \mathrm{KCl}$, and $\geq 24 \%$ activity in $30 \%(\mathrm{v} / \mathrm{v})$ of methanol in $1-2 \mathrm{M} \mathrm{KCl}$. Interestingly, at 
359 low salt concentration $(0.1 \mathrm{M} \mathrm{KCl})$, DMSO increased the activity of ADH/D1 by 200\%

360 (Supplementary Figure 2f). Moreover, ADH/D1 retained $90 \%$ of its initial activity after $32 \mathrm{~h}$ of

361 incubation with 30\% (v/v) DMSO at room temperature (Figure 3f).

362 As expected for a halophilic enzyme, ADH/D1 dialyzed against water was inactive. However,

$363 \mathrm{ADH} / \mathrm{D} 1$ completely regained its catalytic capacity with the addition of buffers containing $3 \mathrm{M} \mathrm{KCl}$.

364 (Supplementary Figure 4e). ADH/D1's capacity to withstand the absence of salt for long periods

$365\left(>12 \mathrm{~h}\right.$ at $\left.4^{\circ} \mathrm{C}\right)$ without irreversible aggregation is unprecedented among halophilic proteins and might

366 result from the dual halo- and thermophilic adaptations. Moreover, ADH/D1 could be lyophilized

367 directly within its high-salt reaction buffer, and it entirely recovered its activity after dissolving the

368 enzyme-salt mixture in water (Supplementary Figure 4f).

369

370 The combination of activity and stability in the presence of different solvents, as well as the 371 possibility that $\mathrm{ADH} / \mathrm{D} 1$ can be stored and used as a powder, are promising features for its synthetic 372 and biotechnological implementations.

\section{Conclusion}

375 SAGs generate a trove of undescribed proteins, including enzymes from unculturable extremophiles.

376 These molecules may combine exceptional stability with unusual functions and could therefore

377 inspire novel biotechnological applications. Nonetheless, this source of proteins has not yet been used

378 for targeted experimental investigations on the protein level, because of a lack of trust in the sequence

379 data, difficulties of the data mining processes, and difficulties with protein expression ${ }^{26}$. The

380 methodology reported here enabled the functional and structural analysis of a SAG-derived archaeal

381 halo-thermophilic ADH.

382 Our experimental characterization of ADH/D1 revealed a unique environmental adaptation to use

$383 \mathrm{Mn}^{2+}$ as a cofactor and a rare cofactor dihydroxy modification under aerobic conditions. The

384 structural analysis suggested a mechanism for this modification, enabled by a nearby histidine. The 
385 structural comparison to homologs allowed the features that confer the exceptional stability of

$386 \mathrm{ADH} / \mathrm{D} 1$ to be identified.

387 The roadmap and proof-of-concept we provide here may alter the way enzymes are obtained, away

388 from the traditional culture- and activity-based methods toward new and more reliable annotation

389 methods. In this view, SAGs, but not metagenomics, offers the possibility of studying many enzymes

390 from the same species. Hence SAGs could allow for the reconstruction of multi-protein complexes or

391 metabolic pathways and provide genes for one-pot multistep reactions involving several enzymes.

392 


\section{METHODS}

\section{Source and annotation of brine pool SAGs}

395 Genomic data were sampled and prepared as described earlier ${ }^{15}$. Genes were annotated using PPMA $^{9}$

396 and INDIGO ${ }^{10}$. BRENDA ${ }^{14}$ was used to obtain EC numbers for $A D H$.

\section{Codon analysis}

399 Analysis was performed using CUSP(1e), a part of the "Nucleic:Codon usage" command group, from 400 EMBOSS $^{27}$. Data: main chromosomes of $H f x$. volcanii DS2 (14491 contigs) ${ }^{28}$ and Halobacterium sp.

$401 \quad$ NRC-1 (9857 contigs) $)^{29}$.

402

403 Strains, expression, and purification

$404 H f x$. volcanii H1895 and pTA963 ${ }^{30}$ were obtained from T. Allers (University of Nottingham, UK).

405 Synthetic genes were codon-optimized using the Eurofins Genomics software for E. coli K12, or

$406 \mathrm{JCat}^{31}$ set for Halobacterium sp. NRC-1. Constructs contained an N-terminal his ${ }_{6}$-tag. The $H f x$.

407 volcanii-optimized gene, from Geneart, was cloned into pTA963. The E. coli codon-optimized gene,

408 from Eurofins, was cloned into pET28b. YqhD (in pDEST17) was obtained from G. Sulzenbacher

409 (Universités d'Aix-Marseille, France). Protein production and purification in E. coli by HisTrap $5 \mathrm{~mL}$

410 columns (GE-Healthcare) were done according to the manufacturer's instructions. YqhD storage

411 buffer: $0.5 \mathrm{M} \mathrm{NaCl}, 50 \mathrm{mM}$ Tris-HCl, $\mathrm{pH}$ 7.4. Protein production and purification in $H f x$. volcanii

$412 \mathrm{H} 1895$ were done as described earlier, ${ }^{9,}$. ADH/D1 storage buffer: $2 \mathrm{M} \mathrm{NaCl}, 20 \mathrm{mM}$ HEPES, pH

413 7.5. Protein mass was determined by Microflex MALDI-TOF (Bruker Daltonics).

414

415 H277A mutant

416 A QuikChange Site-Directed Mutagenesis Kit (Agilent Technologies) was used according to the 417 manufacturer's instructions with the primer 5'-gccgctgatgggggcggccatggcgtgg-3' and its reverse 418 complement on pTA963-ADH/D1. 


\section{Metal substitution}

421 The protein was dialyzed at $4^{\circ} \mathrm{C}$ overnight against the storage buffer first with $10 \mathrm{mM}$ EDTA and then

422 without EDTA. The following metal salts were used: $\mathrm{MgCl}_{2}, \mathrm{CrCl}_{2}, \mathrm{MnCl}_{2}, \mathrm{MnSO}_{4}, \mathrm{FeC}_{2} \mathrm{O}_{4} \cdot 2 \mathrm{H}_{2} \mathrm{O}$, $423\left(\mathrm{NH}_{4}\right)_{2} \mathrm{Fe}\left(\mathrm{SO}_{4}\right)_{2} \cdot 6 \mathrm{H}_{2} \mathrm{O}, \mathrm{CoCl}_{2}, \mathrm{NiSO}_{4}, \mathrm{CuSO}_{4}, \mathrm{ZnCl}_{2}, \mathrm{ZnSO}_{4}, \mathrm{YCl}_{3}, \mathrm{SmCl}_{3}, \mathrm{HoCl}_{3}, \mathrm{Ce}\left(\mathrm{SO}_{4}\right)_{2}$. Before

424 the activity measurements, the protein was incubated with a 20 -fold excess of metal salts for 30 min at 425 room temperature. $\mathrm{Fe}^{2+}$ protein substitution was done under a nitrogen atmosphere.

\section{Activity measurements}

428 The $\mathrm{ADH} / \mathrm{D} 1$ oxidative step included $3 \mathrm{M} \mathrm{KCl}, 12 \mathrm{mM} \mathrm{NAD}^{+}, 50 \mathrm{mM}$ glycine at $\mathrm{pH}$ 10.0. The

429 reductive step included $3 \mathrm{M} \mathrm{KCl}, 0.2 \mathrm{mM} \mathrm{NADH}, 50 \mathrm{mM}$ citric acid $-\mathrm{K}_{2} \mathrm{HPO}_{4}$ at $\mathrm{pH}$ 7.5. The $\mathrm{YqhD}$

430 oxidative step included $0.5 \mathrm{M} \mathrm{NaCl}, 50 \mathrm{mM}$ Tris at $\mathrm{pH}$ 10.0. The ADH/D1 BME oxidative step

431 included $2 \mathrm{M} \mathrm{KCl}, 1 \mathrm{mM} \mathrm{BME}, 4 \mathrm{mM} \mathrm{NAD}^{+}, 50 \mathrm{mM}$ Tris- $\mathrm{HCl}$ at $\mathrm{pH}$ 7.7. During all steps, $0.35 \mu \mathrm{M}$

432 enzyme and $4 \%$ o (v/v) substrate were used at $60^{\circ} \mathrm{C}$. Conditions were altered if indicated.

433 Measurements were conducted on a Cary 60 (Agilent) with an EH heater and F12 water bath (Julabo)

434 or on a Infinite ${ }^{\circledR} 200$ PRO (Tecan) microplate reader.

435 Solvent activity: indicated amounts of DMSO, methanol or THF were added, and the solution was

436 carefully mixed. Salt reactivation: protein was dialyzed against the indicated low salt buffer overnight

437 at $4^{\circ} \mathrm{C}$ before the measurement. Kinetic parameters were calculated using GraphPad Prism V6.00.

\section{Product conversion}

440 Analysis was done using the 7890A GC-FID and the J\&W HP-5ms Ultra Inert column, $30 \mathrm{~m}$,

$4410.25 \mathrm{~mm}, 0.25 \mu \mathrm{m}$ (Agilent Technologies). The helium flow rate was $3.57 \mathrm{~mL} \mathrm{~min}^{-1}$. The temperature

442 program used was $3 \mathrm{~min}$ at $80^{\circ} \mathrm{C}$, ramping with $25^{\circ} \mathrm{C} \mathrm{min}^{-1}$ to $280^{\circ} \mathrm{C}, 6 \mathrm{~min}$ at $280^{\circ} \mathrm{C}$. Before

443 injection, the reaction solution $(10 \mathrm{~mL})$ was extracted with ethyl acetate $(3 \times 10 \mathrm{~mL})$. The combined

444 organic phase was flushed through a silica column.

445

\section{Stability measurements}


447 Solvent: $15.4 \mu \mathrm{g} \mathrm{mL}^{-1}$ enzyme in storage buffer was pre-incubated at room temperature with the

448 indicated amounts of organic solvent. Activity was measured at the specified times.

449 Salt and solvent: The enzyme was dialyzed against a storage buffer overnight at $4^{\circ} \mathrm{C}$ with the 450 indicated amounts of $\mathrm{NaCl}$, then reconstituted with the indicated concentrations of $\mathrm{NaCl}$ or organic 451 solvents before activity measurements. Thermal stability: The enzyme was incubated at the indicated 452 temperatures and the activity was measured at indicated time points.

453

\section{Aggregation temperature}

455 The stargazer $2^{\mathrm{TM}}$ (Harbinger Biotechnology) instrument was used following the manufacturer's 456 instructions with $1 \mathrm{mg} \mathrm{mL}^{-1}$ protein, preincubated with indicated amounts of $\mathrm{Zn}^{2+}$ or $\mathrm{Mn}^{2+}$ at room 457 temperature for $30 \mathrm{~min}$.

458

459

460

461

462

463

464

465

466

467

\section{Lyophilisation}

A $100 \mu \mathrm{L}$ sample (frozen in liquid nitrogen) was lyophilized using a benchtop K lyophilizer (VirTis, SP Scientific) for $2 \mathrm{~h}$. Prior activity measurement: the sample was reconstituted in $100 \mu \mathrm{L}$ of water.

\section{Crystallization and structure determination}

$\mathrm{ADH} / \mathrm{D} 1$ was dialyzed against $50 \mathrm{mM} \mathrm{NaCl}, 20 \mathrm{mM}$ HEPES at $\mathrm{pH}$ 7.5. Crystals were grown at $20^{\circ} \mathrm{C}$ for 3 days, using the sitting drop vapor diffusion method and an ADH/D1 concentration of $20 \mathrm{mg} \mathrm{mL}^{-}$ ${ }^{1}$. If indicated, up to $1 \mathrm{mM}$ of $\mathrm{MnCl}_{2}$ and/or cofactor $(\mathrm{NAD}(\mathrm{H}), \mathrm{NADP}(\mathrm{H}))$ were added. The drops contained equal volumes of protein solution and reservoir solution (150 mM Mg-acetate, 25$30 \%(\mathrm{v} / \mathrm{v})$ methyl-pentane-diol, $100 \mathrm{mM} \mathrm{Na}$ cacodylate $\mathrm{pH}$ 6.5).

Diffraction data sets were recorded with $\lambda=1.0 \AA$, either at the X06SA beamline, SLS, PSI (Villigen, Switzerland) or at the Proxima 1 beamline, SOLEIL (Saint-Aubin, France). Datasets were processed using $\mathrm{XDS}^{32}$ and checked for contaminant proteins (ContaMiner) ${ }^{33} . \mathrm{MoRDa}^{34}$ was used for molecular replacement with $3 \mathrm{bfj}$ as the template. The model was refined with REFMAC ${ }^{35}$ (Table 2). Structures were visualized using PyMOL (Schrödinger). 
476 Table 2: Crystallographic data and refinement statistics (values in parentheses are for the highest

477 resolution shell)

\begin{tabular}{|c|c|c|c|}
\hline & ADH/D1 & ADH/D1 H277A & $\begin{array}{c}\text { ADH/D1 NZQ replaced } \\
\text { after dialysis }\end{array}$ \\
\hline data collection beamline & SLS/X06SA & \multicolumn{2}{|c|}{ SOLEIL/PROXIMA I } \\
\hline wavelength $(\AA)$ & 0.98 & 0.98 & 0.98 \\
\hline $\begin{array}{l}\text { space group } \\
\text { unit cell dimensions }\end{array}$ & C 2221 & C 2221 & C 2221 \\
\hline$a, b, c(\AA)$ & $\begin{array}{r}57.19,103.72 \\
128.51\end{array}$ & $58.05,104.8,129.54$ & $57.92,104.84,129.36$ \\
\hline$\alpha, \beta, \gamma(\operatorname{deg})$ & $90,90,90$ & $90,90,90$ & $90,90,90$ \\
\hline resolution range $(\AA)$ & $\begin{array}{l}48.09-2.12 \\
(2.20-2.12)\end{array}$ & $\begin{array}{r}48.58-1.90 \\
(1.95-1.90)\end{array}$ & $\begin{array}{l}48.58-2.35 \\
(2.41-2.35)\end{array}$ \\
\hline no. of reflections & $21120(2104)$ & $31652(2206)$ & $16847(1176)$ \\
\hline $\mathrm{R}_{\text {merge }}$ & $0.059(0.52)$ & $0.053(2.23)$ & $0.14(1.91)$ \\
\hline $\mathrm{CC} 1 / 2$ & $1.00(0.84)$ & $1.00(0.52)$ & $1.00(0.52)$ \\
\hline $\mathrm{I} / \sigma(\mathrm{I})$ & $11.96(2.27)$ & $14.9(0.8)$ & $8.8(0.8)$ \\
\hline completeness $(\%)$ & $96(97)$ & $99.6(94.2)$ & $99.5(94.1)$ \\
\hline redundancy & $3.6(3.7)$ & $7.4(7.0)$ & $7.2(7.1)$ \\
\hline $\begin{array}{l}\text { refinement } \mathrm{R}_{\text {work }} / \mathrm{R}_{\text {free }}(\%) \\
\text { no. of atoms }\end{array}$ & $17 / 22$ & $18 / 21$ & $22 / 25$ \\
\hline no. of protein atoms & 3055 & 3050 & 3055 \\
\hline no. of water & 106 & 88 & 9 \\
\hline mean B value $\left(\AA^{2}\right)$ & 41.79 & 50.12 & 62.26 \\
\hline RMSD & & & \\
\hline bond length $(\AA)$ & 0.010 & 0.016 & 0.003 \\
\hline bond angles (deg) & 1.05 & 1.29 & 0.57 \\
\hline $\begin{array}{l}\text { Ramachandran analysis } \\
\text { favored region }(\%)\end{array}$ & 96.30 & 96.01 & 96.01 \\
\hline allowed region $(\%)$ & 2.50 & 2.74 & 2.74 \\
\hline outliers $(\%)$ & 1.20 & 1.25 & 1.25 \\
\hline
\end{tabular}

479 Structural analysis and modeling

480 Sequence-based homologs were obtained by I-Tasser ${ }^{36}$, SWISS-MODEL $^{37}$ and PDBsum ${ }^{38}$ and

481 structural homologs from the DALI server ${ }^{39}$ and PDBe Fold v2.59 $9^{40}$. For all homolog searches,

482 duplicates and variants of the same protein were ignored, except for 3owo and 4qgs. Macromolecular

483 interfaces were calculated using PDBe Pisa $^{40}$. Monomeric salt bridges were analyzed using ESBRI ${ }^{41}$.

484 The surface charge for displaying was calculated using PDB2PQR ${ }^{42}$ in combination with the PyMOL

485 plugin APBS $^{43}$. Surface residues $(\geq 5.000 \%$ surface accessibility) were determined using Swiss PDB

486 viewer $4.1^{44}$. Other calculations and addition of hydrogens were done by YASARA. 
487 Modeling: before energy minimizations, pKa prediction was performed for $\mathrm{pH} 7.5$ and 12\% (w/v)

$488 \mathrm{NaCl}$. The AMBER14 force field was used. The open configuration of ADH/D1 was modeled using

489 4QGS with the following parameters: Modeling speed: slow, PsiBLAST: 3, EValue Max: 0.5,

490 Templates Total: 1, Templates SameSeq: 1, OligoState: 1, Alignments: 5, LoopSamples: 200, 491 TermExtension: 10.

492

493 SAXS

494 Data were recorded at the SWING beamline (SOLEIL, Saint-Aubin, France) with $\lambda=1.03 \AA$. The

495 distance of the sample to the detector was $1.8 \mathrm{~m}$, resulting in the momentum transfer range of $0.01 \AA^{-1}$

$496<\mathrm{q}<0.5 \AA^{-1}$. Between $30-50 \mu \mathrm{L}$ of protein was used. For each sample, three concentrations and two

497 buffer blanks were measured. Protein and buffer data were selected and averaged. Buffer data were

498 subtracted from the protein data using SWING's on-site software. ATSAS ${ }^{45}$ was used for data

499 processing, Guinier plots, and distance distributions. ADH/D1 models including the his ${ }_{6}$-tag (not

500 defined in the protein crystals) were prepared using YASARA. FOXS ${ }^{46}$ was used to obtain the fit of 1 ,

5012 or 3 -state ensemble models.

502

503 Accession codes

504 PDB: ADH/D1: 5yvm, ADH/D1-H277A: 5yvr, ADH/D1 NZQ replaced after dialysis: 5yvs 


\section{Acknowledgement}

507 The authors thank the staff of the beamline X06SA at the Paul Scherrer Institute, SLS, Villigen

508 (Switzerland), and beamline staff from the SWING and PROXIMA I beamline of the SOLEIL

509 Synchrotron, France, for assistance during data collection. We thank M. Uludag for assistance in the

510 usage of command line programs and V. Unkefer and S. Almahdali for proofreading.

511 


\section{Supporting Information}

513

514 The Supporting Information is available free of charge on the ACS Publications website.

515

516 Supplementary Figures 1-5 and Supplementary Tables 1-8.

517 


\section{Funding sources}

519 The research reported in this publication was supported by the King Abdullah University of Science

520 and Technology (KAUST) through the baseline fund and the Office of Sponsored Research (OSR)

521 under award nos. URF/1/1976-06, URF/1/2602-01-01, and URF/1/1974. The authors are thankful for

522 support for E.S. and S.G. from the International Graduate School of Science and Engineering

523 (IGGSE), Technical University of Munich (TUM), project 8.03.

524 


\section{References}

526

527

528

529

530

531

532

533

534

535

536

537

538

539

540

541

542

543

544

545

546

547

548

549

550

551

552

553

554

555

556

557

558

559

560

561

562

563

564

565

566

567

568

569

570

571

1. Lockhart, D. J., and Winzeler, E. A. (2000) Genomics, gene expression and DNA arrays Nature 405, 827- 836

2. Rinke, C., Schwientek, P., Sczyrba, A., Ivanova, N. N., Anderson, I. J., Cheng, J. F., Darling, A., Malfatti, S., Swan, B. K., Gies, E. A., Dodsworth, J. A., Hedlund, B. P., Tsiamis, G., Sievert, S. M., Liu, W. T., Eisen, J. A., Hallam, S. J., Kyrpides, N. C., Stepanauskas, R., Rubin, E. M., Hugenholtz, P., and Woyke, T. (2013) Insights into the phylogeny and coding potential of microbial dark matter Nature 499, 431- 437

3. Simon, C., and Daniel, R. (2011) Metagenomic analyses: past and future trends Appl. Environ. Microbiol. 77, 1153- 1161

4. Amann, R. I., Ludwig, W., and Schleifer, K. H. (1995) Phylogenetic Identification and in-Situ Detection of Individual Microbial-Cells without Cultivation Microbiol. Rev. 59, 143- 169

5. Marcy, Y., Ouverney, C., Bik, E. M., Losekann, T., Ivanova, N., Martin, H. G., Szeto, E., Platt, D., Hugenholtz, P., Relman, D. A., and Quake, S. R. (2007) Dissecting biological "dark matter" with single-cell genetic analysis of rare and uncultivated TM7 microbes from the human mouth Proc. Natl. Acad. Sci. U. S. A. 104, 11889- 11894

6. Elleuche, S., Schroder, C., Sahm, K., and Antranikian, G. (2014) Extremozymes - biocatalysts with unique properties from extremophilic microorganisms Curr. Opin. Biotechnol. 29, 116- 123

7. Rashid, M., and Stingl, U. (2015) Contemporary molecular tools in microbial ecology and their application to advancing biotechnology Biotechnol. Adv. 33, 1755- 1773

8. Mason, O. U., Hazen, T. C., Borglin, S., Chain, P. S., Dubinsky, E. A., Fortney, J. L., Han, J., Holman, H. Y., Hultman, J., Lamendella, R., Mackelprang, R., Malfatti, S., Tom, L. M., Tringe, S. G., Woyke, T., Zhou, J., Rubin, E. M., and Jansson, J. K. (2012) Metagenome, metatranscriptome and single-cell sequencing reveal microbial response to Deepwater Horizon oil spill The ISME Journal 6, 1715- 1727

9. Grötzinger, S. W., Alam, I., Alawi, W. B., Bajic, V. B., Stingl, U., and Eppinger, J. (2014) Mining a database of single amplified genomes from Red Sea brine pool extremophilesimproving reliability of gene function prediction using a profile and pattern matching algorithm (PPMA) Front. Microbiol. 5, 134 DOI: 10.3389/fmicb.2014.00134

10. Alam, I., Antunes, A., Kamau, A. A., Kalkatawi, M., Stingl, U., and Bajic, V. B. (2013) INDIGO-INtegrated Data Warehouse of MIcrobial GenOmes with Examples from the Red Sea Extremophiles PloS One 8, e82210 DOI: 10.1371/journal.pone.0082210

11. Steven, C. (2014) Global Market for Industrial Enzymes to Reach Nearly $\$ 7.1$ Billion by 2018; Detergent Enzyme Market to Record Maximum Growth, in Global Markets for Enzymes in Industrial Applications (BIO030H), pp 1-170, BCC Research LLC, Wellesley

12. Friest, J. A., Maezato, Y., Broussy, S., Blum, P., and Berkowitz, D. B. (2010) Use of a robust dehydrogenase from an archael hyperthermophile in asymmetric catalysis-dynamic reductive kinetic resolution entry into (S)-profens J. Am. Chem. Soc. 132, 5930- 5931

13. Yakushi, T., and Matsushita, K. (2010) Alcohol dehydrogenase of acetic acid bacteria: structure, mode of action, and applications in biotechnology Appl. Microbiol. Biotechnol. 86, 1257- 1265

14. Schomburg, I., Chang, A., Ebeling, C., Gremse, M., Heldt, C., Huhn, G., and Schomburg, D. (2004) BRENDA, the enzyme database: updates and major new developments Nucleic Acids Res. 32, D431- 433

15. Mwirichia, R., Alam, I., Rashid, M., Vinu, M., Ba-Alawi, W., Anthony Kamau, A., Kamanda Ngugi, D., Goker, M., Klenk, H. P., Bajic, V., and Stingl, U. (2016) Metabolic traits of an uncultured archaeal lineage -MSBL1- from brine pools of the Red Sea Sci. Rep. 6, 19181 DOI: $10.1038 /$ srep 19181 
572 16. Strillinger, E., Grötzinger, S. W., Allers, T., Eppinger, J., and Weuster-Botz, D. (2016)

573

574

575

576

577

578

579

580

581

582

583

584

585

586

587

588

589

590

591

592

593

594

595

596

597

598

599

600

601

602

603

604

605

606

607

608

609

610

611

612

613

614

615

616

617

618
Production of halophilic proteins using Haloferax volcanii H1895 in a stirred-tank bioreactor Appl. Microbiol. Biotechnol. 100, 1183- 1195

17. Karan, R., Capes, M. D., and DasSarma, S. (2012) Function and biotechnology of extremophilic enzymes in low water activity Aquat. Biosyst. 8

18. Graziano, G., and Merlino, A. (2014) Molecular bases of protein halotolerance Biochim. Biophys. Acta. 1844, 850- 858

19. Kumar, S., Tsai, C. J., and Nussinov, R. (2000) Factors enhancing protein thermostability Protein Eng. 13, 179- 191

20. Vieille, C., and Zeikus, G. J. (2001) Hyperthermophilic enzymes: sources, uses, and molecular mechanisms for thermostability Microbiol. Mol. Biol. Rev. 65, 1- 43

21. Sulzenbacher, G., Alvarez, K., Van Den Heuvel, R. H., Versluis, C., Spinelli, S., Campanacci, V., Valencia, C., Cambillau, C., Eklund, H., and Tegoni, M. (2004) Crystal structure of E.coli alcohol dehydrogenase YqhD: evidence of a covalently modified NADP coenzyme J. Mol. Biol. 342, 489- 502

22. Bougouffa, S., Yang, J. K., Lee, O. O., Wang, Y., Batang, Z., Al-Suwailem, A., and Qian, P. Y. (2013) Distinctive microbial community structure in highly stratified deep-sea brine water columns Appl. Environ. Microbiol. 79, 3425-3437

23. Pierret, M. C., Clauer, N., Bosch, D., Blanc, G., and France-Lanord, C. (2001) Chemical and isotopic (Sr-87/Sr-86, delta O-18, delta D) constraints to the formation processes of Red-Sea brines Geochim. Cosmochim. Acta 65, 1259- 1275

24. Plapp, B. V. (2010) Conformational changes and catalysis by alcohol dehydrogenase Arch. Biochem. Biophys. 493, 3- 12

25. Raj, S. B., Ramaswamy, S., and Plapp, B. V. (2014) Yeast alcohol dehydrogenase structure and catalysis Biochemistry 53, 5791- 5803

26. Sarmiento, F., Peralta, R., and Blamey, J. M. (2015) Cold and Hot Extremozymes: Industrial Relevance and Current Trends Front. Bioeng. Biotechnol. 3, 148 DOI: 10.3389/fbioe.2015.00148

27. Olson, S. A. (2002) EMBOSS opens up sequence analysis. European Molecular Biology Open Software Suite Brief. Bioinform. 3, 87-91

28. Hartman, A. L., Norais, C., Badger, J. H., Delmas, S., Haldenby, S., Madupu, R., Robinson, J., Khouri, H., Ren, Q. H., Lowe, T. M., Maupin-Furlow, J., Pohlschroder, M., Daniels, C., Pfeiffer, F., Allers, T., and Eisen, J. A. (2010) The Complete Genome Sequence of Haloferax volcanii DS2, a Model Archaeon PloS One 5, e9605 DOI: 10.1371/journal.pone.0009605

29. Ng, W. V., Kennedy, S. P., Mahairas, G. G., Berquist, B., Pan, M., Shukla, H. D., Lasky, S. R., Baliga, N. S., Thorsson, V., Sbrogna, J., Swartzell, S., Weir, D., Hall, J., Dahl, T. A., Welti, R., Goo, Y. A., Leithauser, B., Keller, K., Cruz, R., Danson, M. J., Hough, D. W., Maddocks, D. G., Jablonski, P. E., Krebs, M. P., Angevine, C. M., Dale, H., Isenbarger, T. A., Peck, R. F., Pohlschroder, M., Spudich, J. L., Jung, K. W., Alam, M., Freitas, T., Hou, S., Daniels, C. J., Dennis, P. P., Omer, A. D., Ebhardt, H., Lowe, T. M., Liang, P., Riley, M., Hood, L., and DasSarma, S. (2000) Genome sequence of Halobacterium species NRC-1 Proc. Natl. Acad. Sci. U. S. A. $97,12176-12181$

30. Stroud, A., Liddell, S., and Allers, T. (2012) Genetic and biochemical identification of a novel single-stranded DNA-binding complex in Haloferax volcanii, Front. Microbiol. 3, 224 DOI: 10.3389/fmicb.2012.00224

31. Grote, A., Hiller, K., Scheer, M., Munch, R., Nortemann, B., Hempel, D. C., and Jahn, D. (2005) JCat: a novel tool to adapt codon usage of a target gene to its potential expression host Nucleic Acids Res. 33, W526- W531 
633

634

635

636

637

638

639

640

641

642

643

644

645

646

647

648

649

650

651

652

653

654

655

656

657

658

659

660

661

32. Kabsch, W. (1993) Automatic Processing of Rotation Diffraction Data from Crystals of Initially Unknown Symmetry and Cell Constants J. Appl. Crystallogr. 26, 795- 800

33. Hungler, A., Momin, A., Diederichs, K., and Arold, S. T. (2016) ContaMiner and ContaBase: a webserver and database for early identification of unwantedly crystallized protein contaminants $J$. Appl. Crystallogr. 49, 2252-2258

34. Vagin, A., and Lebedev, A. (2015) MoRDa, an automatic molecular replacement pipeline Acta Crystallogr. A71, 19

35. Vagin, A. A., Steiner, R. A., Lebedev, A. A., Potterton, L., McNicholas, S., Long, F., and Murshudov, G. N. (2004) REFMAC5 dictionary: organization of prior chemical knowledge and guidelines for its use Acta Crystallogr. D 60, 2184-2195

36. Roy, A., Kucukural, A., and Zhang, Y. (2010) I-TASSER: a unified platform for automated protein structure and function prediction Nat. Protoc. 5, 725- 738

37. Biasini, M., Bienert, S., Waterhouse, A., Arnold, K., Studer, G., Schmidt, T., Kiefer, F., Gallo Cassarino, T., Bertoni, M., Bordoli, L., and Schwede, T. (2014) SWISS-MODEL: modelling protein tertiary and quaternary structure using evolutionary information Nucleic Acids Res. 42, W252- 258

38. Laskowski, R. A., Chistyakov, V. V., and Thornton, J. M. (2005) PDBsum more: new summaries and analyses of the known 3D structures of proteins and nucleic acids Nucleic Acids Res. 33, D266- 268

39. Holm, L., and Rosenstrom, P. (2010) Dali server: conservation mapping in 3D Nucleic Acids Res. 38 , W545- 549

40. Velankar, S., Alhroub, Y., Alili, A., Best, C., Boutselakis, H. C., Caboche, S., Conroy, M. J., Dana, J. M., van Ginkel, G., Golovin, A., Gore, S. P., Gutmanas, A., Haslam, P., Hirshberg, M., John, M., Lagerstedt, I., Mir, S., Newman, L. E., Oldfield, T. J., Penkett, C. J., Pineda-Castillo, J., Rinaldi, L., Sahni, G., Sawka, G., Sen, S., Slowley, R., Sousa da Silva, A. W., Suarez-Uruena, A., Swaminathan, G. J., Symmons, M. F., Vranken, W. F., Wainwright, M., and Kleywegt, G. J. (2011) PDBe: Protein Data Bank in Europe Nucleic Acids Res. 39, D402- 410

41. Costantini, S., Colonna, G., and Facchiano, A. M. (2008) ESBRI: a web server for evaluating salt bridges in proteins Bioinformation 3, 137- 138

42. Dolinsky, T. J., Czodrowski, P., Li, H., Nielsen, J. E., Jensen, J. H., Klebe, G., and Baker, N. A. (2007) PDB2PQR: expanding and upgrading automated preparation of biomolecular structures for molecular simulations Nucleic Acids Res. 35, W522- 525

43. Baker, N. A., Sept, D., Joseph, S., Holst, M. J., and McCammon, J. A. (2001) Electrostatics of nanosystems: application to microtubules and the ribosome Proc. Natl. Acad. Sci. U. S. A. 98, 10037- 10041

44. Guex, N., and Peitsch, M. C. (1997) SWISS-MODEL and the Swiss-PdbViewer: an environment for comparative protein modeling Electrophoresis 18, 2714- 2723

45. Petoukhov, M. V., Franke, D., Shkumatov, A. V., Tria, G., Kikhney, A. G., Gajda, M., Gorba, C., Mertens, H. D., Konarev, P. V., and Svergun, D. I. (2012) New developments in the ATSAS program package for small-angle scattering data analysis $J$ Appl Crystallogr. 45, 342- 350

46. Schneidman-Duhovny, D., Hammel, M., Tainer, J. A., and Sali, A. (2016) FoXS, FoXSDock and MultiFoXS: Single-state and multi-state structural modeling of proteins and their complexes based on SAXS profiles Nucleic Acids Res. 44, W424- 429 